\title{
SISTEMA(S) DE AVALIAÇÃO DA EDUCAÇÃO SUPERIOR BRASILEIRA
}

Nelson de Abreu Júnior*

\begin{abstract}
RESUMO: O presente artigo busca contribuir para a discussão das políticas públicas ligadas à avaliação institucional brasileira, nas duas versões mais recentes do denominado Sistema Nacional de Avaliação da Educação Superior. A primeira foi implantada no governo de Fernando Henrique Cardoso e a segunda, aprimorada no governo de Lula da Silva. Ambas têm como referência o contexto das demandas sociais de expansão da matrícula na educação superior, a incapacidade do Estado brasileiro em atendê-las, a consequente privatização incremental na matrícula daquele nível de ensino e um provável jogo de cena para aparentar certa regulação da qualidade na oferta do ensino. Na última parte, indica a retomada da avaliação brasileira nos moldes do Programa de Avaliação das Instituiçôes Universitárias Brasileiras (PAIUB), separando radicalmente a avaliação da regulação.
\end{abstract}

Palavras-chave: Avaliação institucional. Sistema brasileiro de avaliação da educação superior. Qualidade acadêmica.

\section{BRAZILIAN HIGHER EDUCATION ASSESSMENT SYSTEM(s)}

ABSTRACT: This paper contributes to the discussion on public policies linked to the last two versions of Brazilian institutional assessment, called National Assessment System of Higher Education. The first one was implanted by Fernando Henrique Cardoso's administration, and the second one improved by Lula's government. Both are referred to the context of the social demand for expansion and diversification of school registration in higher education, the Brazilian State incapacity to meet them,

Mestre em Ciências da Educação e diretor da Unidade de Ciências Socioeconômicas e Humanas da Universidade Estadual de Goiás (UEG).E-mail: nelsonabreu@ueg.br 
the consequent growing privatization of that education level and a probable make-believe intended to exhibit a certain regulation of the quality of education provision. Its last part considers the rescue of Brazilian assessment in the molds of the Program of Assessment of the Brazilian Institutional Universities (PAIUB) and radically separates assessment from regulation.

Key words: Institutional Assessment. Brazilian higher education assessment system. Academic quality.

\section{Introdução}

E

ste artigo tem sua origem nos estudos desenvolvidos por um gru-

po de pesquisa que se dedica ao tema da avaliação da educação superior e sua relação com a qualidade do ensino. ${ }^{1}$ A questão da qualidade emerge como questão central, em razão das expectativas que gravitam em torno do papel contemporâneo da educação superior e do valor social assumido pelo conhecimento decorrente das transformaçóes no mundo do trabalho. Questionam-se os modelos de financiamento da universidade pelo Estado e a imposição da crescente racionalização dos processos acadêmicos. A avaliação institucional surge, pois, como um dos pilares da gestão universitária racioanalizada.

O entendimento da atual ênfase conferida à avaliação da qualidade educacional aparece em um contexto de pelo menos três grandes tendências: as novas demandas que a sociedade e a economia projetam sobre os sistemas educativos, no marco da internacionalização, e a busca incessante da competitividade no mercado mundial; a situação econômica que, de modo recorrente, tem afetado a capacidade de atendimento de todas e cada uma das necessidades de ordem social; os resultados dos efeitos das crises econômicas sobre a opinião pública e sobre as ideologias de prestação de contas, que evidenciam a falta de confiança na capacidade do Estado em responder às demandas de uma população cada vez mais exigente (Tiana, Santángelo \& Pedró, 1996).

\section{A qualidade como categoria multirreferencial}

Um dos objetivos básicos dos sistemas de avaliação educacional consiste em melhorar a qualidade das instituições educacionais, ainda 
que conceituar universalmente o termo qualidade seja tarefa ingrata. A qualidade da educação em todos os níveis, segundo Yarzabal, Vila e Ruiz (1999), parece ser um dos requisitos fundamentais do desenvolvimento científico e tecnológico de qualquer país. $\mathrm{O}$ mundo desenvolvido e o mundo em desenvolvimento progridem aceleradamente para novas formas de organizar a produção, distribuição e uso do conhecimento.

Os autores (op. cit.) diferenciam algumas utilizações desse termo, destacando que a qualidade é um princípio relativo, pois o que é considerado qualidade pelo setor acadêmico pode conflitar com a qualidade buscada pelos governos, com aquela percebida pela sociedade ou, então, a que corresponde às demandas do setor produtivo.

$\mathrm{O}$ mundo acadêmico adota, prioritariamente, indicadores e critérios quantitativos para a qualidade, tais como número de professores doutores, de publicaçôes em revistas indexadas, de produções originais das instituições, sobretudo aquelas referentes a teorias e tecnologias inovadoras. A qualidade também é entendida como a menor distância entre o estágio em que a instituição se encontra e o protótipo ideal de instituição.

A sociedade, por sua vez, parece considerar a qualidade diretamente atrelada a fatores como a concorrência nos processos de admissão, a empregabilidade e o sucesso profissional dos seus egressos, a reputação do quadro docente, a suntuosidade das instalações, a aparente, mas nem sempre efetiva, inovação tecnológica dos laboratórios. Estudos mercadológicos contratados por investidores da iniciativa privada em educação superior e divulgados nas publicações especializadas daquele segmento apontaram que certas condições facilitam a escolha do egresso do ensino médio e permanência do estudante na educação superior, tais como a localização da instituição, preço das mensalidades e tempo exigido para a integralização do currículo, e concorrem decisivamente para indicar que instituição melhor condiz com as aspirações do estudante. Tais resultados podem ser observados na publicidade adotada pelas IES do segmento privado.

Uma concepção de qualidade ligada diretamente aos referenciais do mundo da produção considera-a resultante da correlação entre metas, objetivos e resultados, ou seja, a diferença entre o que se quer e o que se alcança. Existem referenciais ainda mais próximos da concepção 
segundo a qual a educação superior é uma forma de prestação de serviços. Como, neste caso, a qualidade é determinada pelo grau de satisfação do usuário, busca-se, então, avaliar a opiniāo dos estudantes, empregadores e egressos. Esta concepção é vista com muita desconfiança pelo mundo acadêmico, sobretudo, por negar a educação como bem público inalienável, por considerar que o cliente da educação é o aluno e não a sociedade e, sobretudo, pela inadequação de seus modelos gerenciais, cujos propósitos institucionais são difusos e não se mostram com a transparência necessária ao julgamento da comunidade acadêmica.

A qualidade, em uma perspectiva multidimensional, está intimamente ligada à missão e aos valores da instituição. São eles que indicam uma situação prospectiva ideal e fazem mover a instituição para diminuir o espaço entre a instituição atual e uma situação desejada. Trata-se de um conceito de qualidade que envolve e compromete os seus integrantes e parece não concorrer com as demais concepções, mas, sim, abarcá-las. Não se concebe, como ideal, uma instituição em que as necessidades dos usuários ou beneficiários não estejam satisfeitas ou que se tenham sistematicamente frustradas as suas expectativas, sem deflagrar uma espécie de crise. Tampouco se considera ideal uma instituição incapaz de estabelecer e cumprir suas metas ou objetivos, ou que não se preocupe com o desempenho e a satisfação de seus egressos no campo laboral.

\section{Os sistemas de avaliação em outros países}

As modalidades de avaliação que vêm sendo implantadas em vários países podem se distinguir segundo as estruturas e as formas de regulação dos sistemas educativos.

Em alguns deles, a autonomia universitária e os investimentos dependem inteiramente dos resultados alcançados em uma avaliação externa, denominada aferição de resultados ou modelo de indicadores. A avaliação se processa pela seleção de um número de indicadores de rendimento que permitam estabelecer uma ordem hierárquica das instituições e de diferentes programas (Both, 1995; Yarzabal, Vila \& Ruiz, 1999). Essa forma de avaliação interfere na autonomia universitária, direcionando políticas internas para que os resultados dos indicadores 
definidos pelo Estado sejam favoráveis, mesmo que isso implique prejuízos qualitativos dos processos acadêmicos.

Outro conjunto de países adota o modelo de autorregulação. Trata-se de uma avaliação realizada pelas próprias instituições, com o propósito de melhorar a sua qualidade. Nesses países, os órgãos de financiamento estabelecem poucas exigências quanto ao nível dos resultados da avaliação interna. O modelo de autorregulação tem sido adotado em muitos países da Europa e da América Latina. Cabe considerar, no entanto, que esta modalidade exige um nível de maturidade das instituições que somente o tempo e o exercício podem proporcionar; impõe aos governos e à sociedade uma espera prolongada, até que os processos autoavaliativos se firmem e se integrem à rotina acadêmica; tem, como vantagem, ser um processo mais democrático, capaz de permitir o desenvolvimento desse princípio no interior da instituição.

A discussão contemporânea sobre a relação entre o governo e as instituiçóes de nível superior na América Latina traz à tona o novo papel do Estado: definir a forma e a função prioritária que os mecanismos de avaliação devem ocupar nas grandes políticas para a educação superior e, de maneira mais ou menos indireta, condicionar a dotação orçamentária ao desempenho institucional. Os sucessivos governos dos países em desenvolvimento queixam-se dos altos custos da universidade pública e, cada vez mais afinados com os organismos internacionais de matizes liberais, questionam a prioridade conferida à sua função social. Talvez por essa razão, houve forte expansão do ensino superior privado no Brasil, nas duas últimas décadas. Atualmente, ele responde por aproximadamente $75 \%$ das matrículas do sistema de educação superior. A despeito das restriçōes orçamentárias do atual governo, há uma forte pressão da sociedade civil para a expansão da matrícula nas universidades públicas, com garantia de qualidade do ensino e da produção científica.

No sistema de avaliação brasileiro, a avaliação da educação superior ganhou relevância no governo de Fernando Henrique Cardoso (1995-2002). Embora o objetivo fosse a implantação de um sistema avaliativo para a melhoria da educação superior, o modelo proposto sofreu resistências por parte da comunidade universitária.

A proposta apresentava três pontos ditos estratégicos: avaliação institucional, com base em diretrizes curriculares estruturadas pelos 
especialistas designados pelo Ministério da Educação, estabelecendo vínculo entre orçamento e desempenho de estudantes e professores; avaliação do desempenho dos professores, estratégia de produtividade que vincula gratificação com desempenho, quebrando a isonomia entre docentes ativos e aposentados; avaliação das habilidades e competências dos estudantes, mediante a realização de Exame Nacional de Cursos (ENC), o denominado "Provão", de caráter de obrigatório, uma vez que dele dependia o registro profissional, e que estabelecia alto grau de competitividade entre estudantes (Cunha, 2003).

Com a nova proposta, o foco da avaliação do ensino superior deslocou-se da dimensão institucional para a individual, centrandose na avaliação dos alunos, e o Programa de Avaliação Institucional das Universidades Brasileiras (PAIUB) - que se tratava inicialmente de uma proposta da Associação Nacional de Dirigentes das Instituições Federais de Educação Superior (ANDIFES) e entre seus princípios destacam-se o compromisso formativo da avaliação, a globalidade, a integração orgânica da autoavaliação com a avaliação externa, a continuidade, a participação ativa da comunidade acadêmica, o respeito à identidade institucional, o reconhecimento da diversidade do sistema e a adesão voluntária das instituições - tendo sido bruscamente interrompido como política pública.

A Lei n. 9 131/95 (Brasil, 1995), que estabeleceu o ENC, em seu artigo 3 dizia que o MEC procederia a "avaliaçôes periódicas das instituições e dos cursos de ensino superior, fazendo uso de procedimentos e critérios abrangentes, dos diversos fatores que determinam a qualidade e a eficiência das atividades de ensino, pesquisa e extensão". Os ENC passaram então a ser obrigatórios para os estudantes do último ano de todos os cursos superiores de graduação. Os resultados relativos a cada instituição de ensino deveriam ser divulgados publicamente, criando uma espécie de ranking da qualidade institucional brasileira.

A veemente resistência da comunidade universitária às primeiras edições do denominado "Provão" induziu à adição de novos componentes avaliativos, tais como a relativização na análise dos principais indicadores de desempenho global do sistema nacional de ensino superior, sendo considerados a região, as unidades da federação, as áreas do conhecimento e o tipo ou a natureza das instituiçóes de ensino. 
Foram introduzidas, ainda, a avaliação do desempenho individual das instituições de ensino superior, nas modalidades de ensino, pesquisa e extensão, e a avaliação de cada curso de graduação, por meio da análise das condições de oferta pelas diferentes instituiçóes de ensino e pela análise dos resultados do ENC.

Para a avaliação das condiçôes da oferta dos cursos de graduação, eram consideradas a organização didático-pedagógica, a adequação das instalações físicas em geral e das instalaçôes especiais, tais como laboratórios, oficinas e outros ambientes indispensáveis à execução do currículo, a qualificação do corpo docente e bibliotecas.

Pode-se afirmar que o governo de Fernando Henrique Cardoso adotou, primordialmente, um modelo de avaliação com base no controle de produtos ou de resultados, no qual o Estado adotava práticas que valoravam o controle de produtos, transferindo para as instituiçóes as tarefas instrumentais. Esse modelo, inserido em uma macropolítica de contração do Estado, conforme as ideias neoliberais, leva à restrição orçamentária e delega ao mercado a manutenção do sistema, reservando-se a prerrogativa de ditar mecanismos básicos de avaliação em detrimento dos processos que incentivem o amadurecimento institucional, como os autoavaliativos. Pode-se afirmar que esse modelo promoveu a demolição do comprometimento e da responsabilidade da comunidade para com o desenvolvimento institucional.

Ao analisarem a dinâmica de alteração no campo universitário brasileiro e o processo de metamorfose das universidades públicas, no final do governo de Fernando Henrique Cardoso, autores como Catani e Oliveira (2002) assinalam que o modelo de expansão adotado no país se distinguia pela diferença no perfil das IEs e pela diversificação e flexibilização da oferta. De acordo com os autores, a expansão tenderia a ampliar-se, no futuro próximo, em consequência das políticas de ajustamento do sistema ao crescimento da demanda e ao atendimento das exigências do mercado.

Dessa forma, o conceito de qualidade adotado naquele governo parece ter privilegiado a empregabilidade e o sucesso profissional dos seus egressos, a suntuosidade das instalações e uma aparente inovação tecnológica nos laboratórios de ensino. A titulação do quadro docente, assim como a sua produção científica perderam importância em face da prioridade conferida ao desempenho dos alunos. 
O Sistema Nacional de Avaliação da Educação Superior (SINAES) substituiu o modelo anterior em 2004. A proposta assumida pelo atual presidente do país, Luiz Inácio Lula da Silva, prometia rever o sistema de avaliação que incluía o ENC e implantar um sistema nacional de avaliação institucional com base, entre outras, na experiência do PAIUB.

A proposta do SINAES teve, como um de seus desafios, aproveitar da melhor maneira possível as experiências existentes no Brasil, melhorando, integrando e otimizando o uso dos instrumentos de informação disponíveis e, ao mesmo tempo, criando outros considerados fundamentais. É importante assinalar a importância do antigo PAIUB, como referência para o novo sistema avaliação. De fato, o SINAES incorporou grande parte dos princípios e diretrizes do PAIUB, notadamente a exceção do princípio da adesão voluntária (Ristoff \& Giolo, 2006).

A qualidade foi também considerada um valor agregado, aferindo-se aquilo que o estudante aprende durante a sua permanência na instituição. Nessa ótica, considera-se que o resultado da graduação está relacionado às competências demonstradas pelos egressos de uma instituição, comparadas àquelas que apresentavam como ingressantes. É uma forma de avaliação externa de produtos, difícil de ser aferida pelo tempo que consome para se determinar um perfil consensual do que é esperado do egresso.

$\mathrm{Na}$ opinião de um de seus idealizadores, Dilvo Ristoff, o SINAES pode ser efetivamente considerado um sistema, uma vez que: integra os instrumentos de avaliação; integra-os aos de informação; integra os espaços de avaliação no MEC; integra a autoavaliação à avaliação externa; articula, sem confundir, avaliação e regulação; propicia coerência entre avaliação e os objetivos e a política para a educação superior. Segundo o autor, a avaliação institucional não se confunde com avaliações de rendimento acadêmico ou de cursos, embora as considere efetivamente em suas análises, inferências e juízos (MEC, 2003).

Para Marchelli (2007), o SINAEs é um importante instrumento cognitivo, crítico e organizador, exigindo a sistematização e o interrelacionamento de um grande conjunto de informaçôes, obtidas por meio de dados quantitativos e juízos de valor, dizendo respeito à qualidade das práticas e da produção teórica das IES.

De fato, é notória a evolução conceitual da avaliação de um governo para outro. De acordo com a proposta do governo de Cardoso, 
os clientes (isto é, o mercado ou mundo do trabalho) do sistema de educação superior são contemplados em suas demandas, ocorrendo então uma qualidade implícita.

Em outra perspectiva, a proposta do SINAES assume o compromisso de ser emancipadora e de articular, sem confundir, as avaliações internas e externas. O documento referente ao SINAES enfatiza: "as ações combinadas de avaliação interna e externa são processos importantes de discussão e reflexão com respeito aos grandes temas de política pedagógica, científica e tecnológica, bem como para tomadas de decisôes (...)" (Brasil, 2003, p. 78).

Entretanto, não foi bem isso que aconteceu na implementação da proposta: os conceitos obtidos pelo atual Exame Nacional de Desempenho dos Estudantes ganharam muito mais notoriedade e centralidade do que a autoavaliação. Aquilo que deveria ser uma referência para a qualidade foi utilizado pelo mercado educacional como diferencial mercadológico.

Em suas reflexões acerca da avaliação institucional, Leite (2005, p. 33) esclarece que esta deveria dedicar-se a "avaliar a instituição como um todo ou as políticas públicas em seu caráter global”. Em outras palavras, não é seu objetivo verificar o desempenho de indivíduos, mas as categorias integradas no contexto da instituição. Dias Sobrinho (2000, p. 103) confirma essa assertiva: "O objeto constituído é a instituição em seu conjunto e de forma articulada. Não se trata de avaliar isoladamente conhecimentos, docentes individuais, estudantes como categoria separada. Trata-se de avaliar a instituição como um todo".

De fato, a necessidade da avaliação nasce da dinâmica de transformação pela qual passa a sociedade atual, seja no campo cultural, seja nos campos político e econômico. Nesse sentido, a avaliação institucional é tida como uma grande força instrumental de gestão. Na práti$\mathrm{ca}$, as questôes técnicas que lhe dizem respeito apenas tocam de leve o seu conteúdo filosófico e político. Isto se explica pelo fato de sua aplicabilidade ser mais complexa, exigindo longa maturação e reflexão permanente por parte da comunidade universitária.

Para que a instituição esteja preparada para enfrentar os desafios contemporâneos, é fundamental que sua realidade, suas virtudes, capacidades e limitações sejam conhecidas pelos seus membros. Somente assim, e com base no diagnóstico de suas condições, é que a tomada 
de decisões poderá ser feita de maneira ética. A avaliação institucional "é um campo de disputas que ultrapassa as questôes mais aparentes e formais da organização e do gerenciamento das instituições educativas", assinala Dias Sobrinho (2000, p. 89). No entanto, o trabalho de acompanhar o cumprimento dos compromissos firmados, no que diz respeito aos reajustes para a autossuperação dos problemas, não tem sido uma tradição nas propostas das universidades brasileiras e latino-americanas e talvez seja, para o caso brasileiro, a inovação mais essencial que o conceito apresenta.

A qualidade institucional preconizada por Grinspun (2001) é aquela que deve rever e aperfeiçoar o projeto político-pedagógico da instituição, mediante a pertinência e a relevância das atividades desenvolvidas na área pedagógica e administrativa. De alguma forma, a avaliação institucional necessita ter a sua continuidade assegurada nas sequências de gestóes. Deve estar intimamente ligada aos processos de planejamento e de tomada de decisão para possibilitar a sua inscrição na vida total da instituição, superar equívocos e promover a qualidade formativa de modo contínuo e permanente. Ao se realizar como elemento perene do processo institucional, instala-se a cultura da avaliação.

\section{Considerações finais}

A avaliação não é um processo meramente técnico e seu sucesso depende, em grande parte, do reconhecimento da legitimidade dos responsáveis por sua realização (Dias Sobrinho, 2000). Os processos avaliativos precisam envolver o maior número de participantes, tanto na construção de seu projeto quanto na análise e no uso dos resultados, contribuindo para o desenvolvimento humano na instituição.

Enquanto a avaliação estiver reduzida à avaliação externa, associada a mecanismos de regulação do sistema e quase sempre focada nos resultados, em detrimento dos processos universitários, ela perde a oportunidade de envolver os participantes na proposição de soluções que garantam a mudança institucional, sobretudo quando a reflexão propiciada pela avaliação busca seus aspectos mais sistêmicos para a superação dos problemas. Por outro lado, a avaliação institucional interna, validada por agentes externos, presta-se a ser um agente de mudança e aprendizagem institucional, desde que garanta a participação coletiva. 
A análise dos princípios do PAIUB deixa perceber que o processo avaliativo permite a reflexão da instituição, em suas variadas dimensões e por seus mais diversos segmentos de pessoal, e deve pautar-se em práticas avaliativas que não registrem apenas momentos isolados de cursos, de programas de estudo, de desempenho de aluno, de práticas pedagógicas, ou que considerem a tarefa docente e o ensino como os únicos elementos sujeitos ao processo de avaliação. Enfim, deve-se buscar uma perspectiva de autoavaliação institucional que contribua para a melhoria de suas múltiplas e contraditórias facetas, pois, ainda reportando-se a Dias Sobrinho (2000, p. 90), "a avaliação institucional tem a ver com a vida das pessoas e o destino da sociedade. Não se pode apenas brincar de fazer avaliação, há vidas de pessoas e de instituições em jogo”.

A avaliação institucional não opera transformações concretas per $s e$, ainda que este seja um elemento de evidência muito poderoso. Ela assume seu sentido mais pleno à medida que estabelece mecanismos responsáveis pelo acompanhamento da implementação de mudanças, prevendo ou identificando obstáculos e propiciando a sua superação.

Se a universidade é uma instituição dinâmica, seus processos avaliativos também o são. $\mathrm{O}$ respeito às singularidades institucionais não recomenda a adoção de medidas ou procedimentos universais, incontestáveis ou absolutos. Se a avaliação permite uma aprendizagem institucional, sendo ela mesma um desses processos, deve conduzir o seu desenvolvimento pela própria avaliação, ou seja, ela deve prever a sua meta-avaliação, em uma busca da coerência interna com seus princípios e finalidades. Trata-se de um conceito que aponta a superação de uma avaliação meramente descritiva da universidade, em favor de um processo de identificação e hierarquização dos problemas, que possibilite o envolvimento dos atores também na busca das soluçóes e que, portanto, colabore para o desenvolvimento humano da instituição e a qualidade acadêmica de seus processos.

Recebido em novembro de 2007 e aprovado em agosto de 2008.

\section{Nota}

1. O presente texto aglutina resultados da pesquisa, coordenada pelo autor, acerca das políticas avaliativas brasileiras e o currículo universitário, da qual participaram, como pesquisadoras, Mirza Seabra Toschi, Eliane Gonçalves Anderi e Virgínia Pereira de Melo. 


\section{Referências}

BOTH, I.J. Processo de avaliação institucional: agente de política universitária. Ensaio: Avaliação e Políticas em Educação, Rio de Janeiro, v. 3, n. 8, p. 253-262, dez. 1995.

BRASIL. Lei n. 9.131, de 24 de novembro de 1995. Altera dispositivos da Lei n. 4024, de 20 de dezembro de 1961, e dá outras providências. Diário Oficial da Uniāo, Brasília, DF, 25 nov. 1995. p. 19257.

BRASIL. Ministério da Educação. Sistema Nacional de Avaliação da Educação Superior (SINAES): bases para uma nova proposta de avaliação da educação superior. Brasília, DF: 2003.

CATANI, A.M.; OLIVEIRA, J.F. Educação superior no Brasil: reestruturação e metamorfose das universidades públicas. Petrópolis: Vozes, 2002.

CATANI, A.M.; OLIVEIRA, J.F.; DOURADO, L.F. A política de avaliação da educação superior no Brasil em questão. Revista da Rede de Avaliação Institucional da Educação Superior, Campinas, v. 6, n. 4, p. 7-16, dez. 2001.

CUNHA L.A. O ensino superior no octênio FHC. Educação \& Sociedade, Campinas, v. 24, n. 82, p. 37-61, abr. 2003.

CUNHA, M.I. (Org.). Formatos avaliativos e concepção de docência. Campinas: Autores Associados, 2005.

DIAS SOBRINHO, J. Avaliação da educação superior. Petrópolis: Vozes, 2000.

GRINSPUN, M.P.S.Z. Avaliação institucional. Ensaio: Avaliação e Políticas em Educação, Rio de Janeiro, v. 9, n. 31, p. 223-236, abr./jun. 2001.

LEITE, D. Reformas universitárias: avaliação institucional participativa. Petrópolis: Vozes, 2005.

MARCHELLI, P.S. External evaluation system of quality standards in higher education in Brazil: consideration about its indicators. Ensaio: Avaliação e Políticas em Educação, Rio de Janeiro, v. 15, n. 56, out. 2007 [online]. 
MOROSINI, M.M. Avaliação do ensino superior: as influências na implantação dos sistemas; os casos brasileiro e português. Revista da Rede de Avaliação Institucional da Educação Superior, Campinas, v. 6, n. 4, p. 35-54, fev. 2001.

RISTOFF, D.; GIOLO, J. O SINAES como sistema. Revista Brasileira de Pós-Graduação, Brasília, DF, v. 3, n. 6, p. 193-213, dez. 2006.

TIANA, A.; SANTÁNGELO, H.; PEDRÓ, F. Evaluación de la calidad de la educación. Revista Iberoamericana de Educación, Madrid, v. 4, n. 10, p. 94-96, fev. 1996.

YARZABAL, L.; VILA, A.; RUIZ, R. Evaluar para transformar. Caracas: IESALC/UNESCO, 1999. 